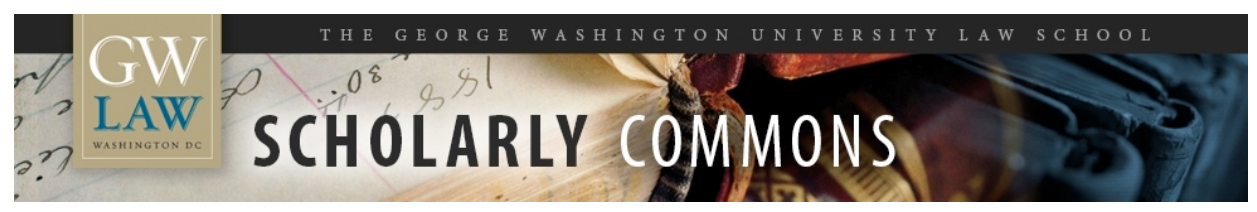

GW Law Faculty Publications \& Other Works

Faculty Scholarship

2019

\title{
Digital Asset Planning for Minors
}

\author{
Natalie Banta \\ Drake University \\ Naomi R. Cahn \\ George Washington University Law School, ncahn@law.gwu.edu
}

Follow this and additional works at: https://scholarship.law.gwu.edu/faculty_publications

Part of the Law Commons

\section{Recommended Citation}

Banta, Natalie and Cahn, Naomi R., Digital Asset Planning for Minors (2019). Natalie Banta \& Naomi R. Cahn, Digital Asset Planning for Minors, Prob. \& Prop., Jan./Feb. 2019, at 44.; GWU Law School Public Law Research Paper No. 2019-1; GWU Legal Studies Research Paper No. 2019-1. Available at SSRN: https://ssrn.com/abstract=

This Article is brought to you for free and open access by the Faculty Scholarship at Scholarly Commons. It has been accepted for inclusion in GW Law Faculty Publications \& Other Works by an authorized administrator of Scholarly Commons. For more information, please contact spagel@law.gwu.edu. 
PROBATE \& PROPERTY A Publication of the Real Property, Trust and Estate Law Section Ai American Bar Association



HOME REPAIR:

A Handy Guide to Fixing a QPRT 


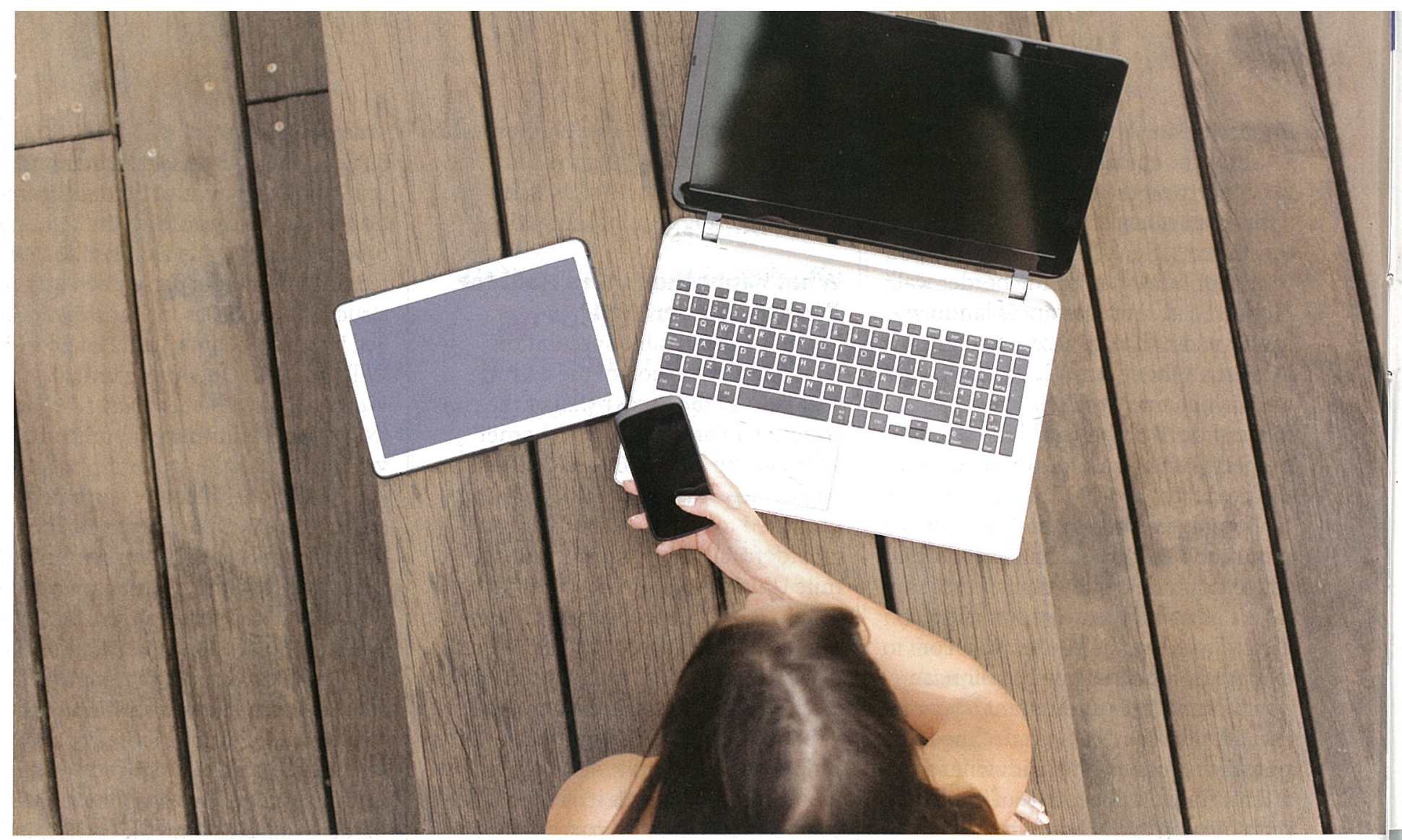

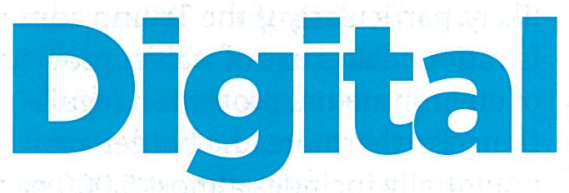
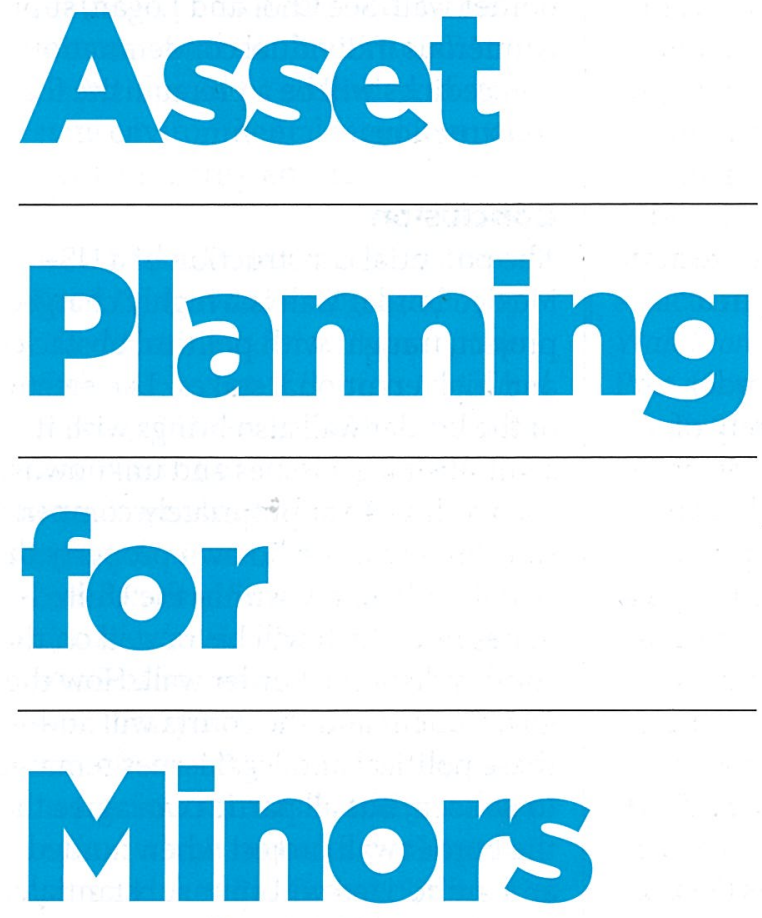

By Natalie Banta and Naomi R. Cahn
T n 2018, Germany's Federal Court of Justice considered whether the parents of a 15-year-old girl who had been killed by a train could access her Facebook account. Her parents wanted to determine whether their daughter's death was accidental or suicidal for legal and personal reasons. Although Facebook opposed access, claiming it needed to protect the account, the court decided that the parents could inherit their daughter's social media accounts just as they could inherit physical property. Daniel Uria, German Court Grants Parents Access to Dead Daughter's Facebook Account, United Press International (July 12, 2018), https://bit.ly/2zuEIDq.

In 2013, an American couple sought access to their son's Facebook account to glean information about his sudden suicide. Facebook resisted, citing various privacy laws, and so the parents petitioned their state legislators to change the law. Virginia became one of the few states to address specifically minors' digital assets accounts, and the statute granted parents access. Virginia's law has subsequently been repealed and replaced by a uniform act (discussed later in this article), but it demonstrates the amount of interest and controversy in determining the fate of minors' digital assets. Fredrick Kunkle, Virginia Family, Seeking Clues to Son's Suicide, Wants Easier Access to Facebook, Wash. Post (Feb. 17, 2013), https://wapo.st/2DQ9bP7.

Minors are digitally plugged in and more computer-literate today than ever before, with almost nine out of ten having access to some type of computer and an even higher number having access to a smartphone. Monica Anderson \& Jinjing Jiang, "Teens, Social Media \& Technology 2018," http://www.pewinternet.org/2018/05/31/

Natalie Banta is an associate professor of law at Drake Law School. Naomi R. Cahn is the associate dean for research and faculty development and Harold H. Greene Professor of Law at The George Washington University Law School. 
teens-social-media-technology-2018. More than 40 percent of children eight and under have a tablet device. Jacqueline Howard, Kids under 9 Spend More than 2 Hours a Day on Screens, Report Shows, CNN.com (Oct. 19, 2017), https://www. cnn.com/2017/10/19/health/childrensmartphone-tablet-use-report/index. html. Children's use and creation of digital assets continue to grow. Companies market their goods and services to minors, and numerous programs are designed to encourage financial savvy among young consumers (e.g., Nimbl, https://nimbl. com/how-it-works). Or consider new toys on the market like "Hello Barbie" from Mattel or "Dino" from Cogni Toys. These web-enabled, interactive toys talk, listen, joke, and respond to children's questions, leaving a digital record of interaction with children as soon as they can talk. The record of a child's play with these interactive toys could be an incredibly valuable
Until recently, most state probate laws did not address digital assets. Since its promulgation in 2015, the Revised Uniform Fiduciary Access to Digital Assets Act (RUFADAA) has been enacted in more than 40 states. It allows fiduciaries to manage a decedent's digital property, such as computer files, web domains, and virtual currency. RUFADAA draws a distinction with respect to a fiduciary's access to electronic communications between the catalogue and the content, precluding access to the latter unless the original user consented in a will, trust, power of attorney, or other record. When the account user has filled out an online tool provided by an internet company that allows the user to give directions for the disposition of digital assets, then the terms of that tool control. In the absence of such a tool, then the terms of a trust, will, power of attorney, or other writing control. And, if there are no directions, then the provider's terms

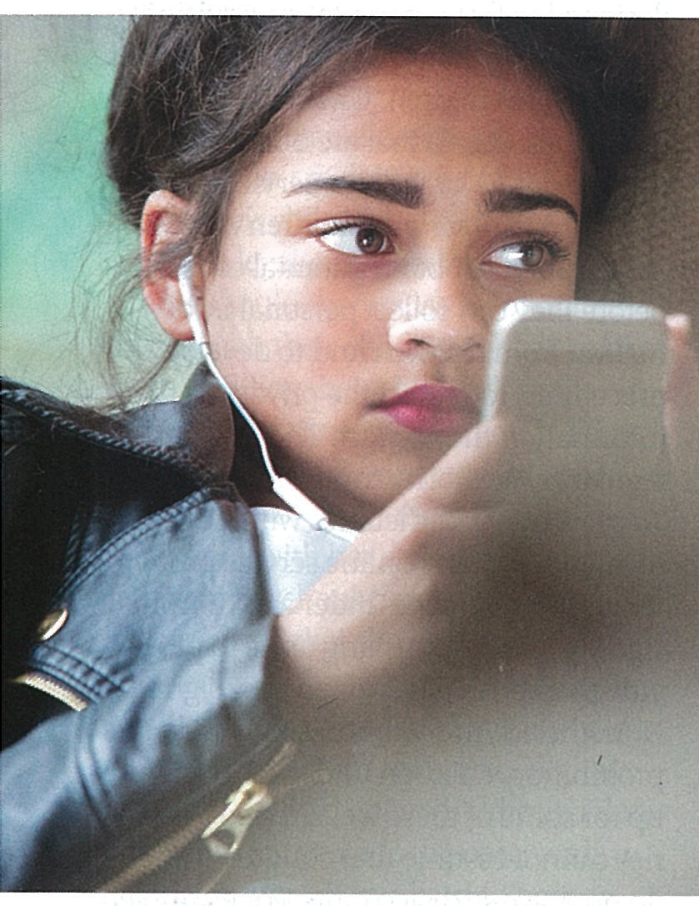

keepsake for a family grieving the death of a child. Parents who seek comfort from their children's digital toys, social media, pictures, documents, and email accounts face an uphill battle in gaining access.

\section{Laws on Digital Access}

Both state and federal laws affect access to digital accounts when the account owner is incapacitated or has died; for minors, there are additional issues. of service control; where they are silent, RUFADAA controls.

Federal law also plays an important role. Congress enacted the Stored Communications Act (SCA) in 1986, when Mark Zuckerberg was two years old. The SCA protects the privacy of the content of certain electronic communications and regulates the conduct of the companies that store electronic communications. Essentially, those online service providers are prohibited from disclosing the contents of a user's communications to a government or nongovernment entity, except under limited circumstances. The restrictions vary, depending on whether the fiduciary seeks catalogue-type information or the contents of an electronic communication. With respect to catalogue-type information, such as the email address of both sender and recipient, and the date and time when the communication was sent, the SCA permits disclosure to a nongovernmental entity.

With respect to the content"information concerning the substance, purport or meaning of that communication," as the SCA defines it-a service provider is prohibited from disclosure to a fiduciary, unless an exception to the SCA applies. For example, disclosure is permitted with the "lawful consent" of either the sender or the recipient/addressee.

The SCA does not protect content that is accessible to the public, but it would cover, for example, a Facebook post that can be viewed only by "friends."

In addition to the SCA, the federal Computer Fraud and Abuse Act imposes civil and criminal liability on someone who "accesses a computer without authorization or exceeds authorized access" and obtains information. 18 U.S.C. $\S$ $1030(\mathrm{a})(2)(\mathrm{C})$. This translates into a requirement that the account owner consent to the person's access and that the terms of service agreement controlling the digital account not preclude access by a third party. States have similar statutes that also present similar barriers.

\section{Special Considerations for Minors}

Moving beyond federal and state law regarding digital assets more generally, there are special considerations when it comes to minors. First are issues concerning the capacity of minors. This is important in two contexts: the capacity of minors to execute a binding estate planning instrument and to enter into a contract with a service provider.

State succession law imposes restrictions on who is considered capable of executing a testamentary instrument. In order to execute a will or trust, an individual must have both legal and mental capacity. Although many minors could 


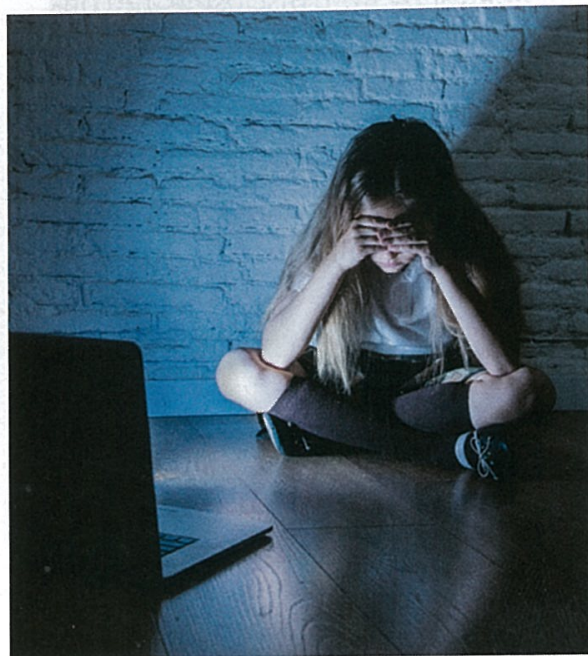

potentially meet the low standard of mental capacity needed to execute a will, most states require an individual to be 18 years old in order to have legal capacity. Historically, the age for legal capacity has fluctuated widely. For example, in medieval England there is evidence that a four-year-old had legal capacity to devise. Some states today grant legal capacity to minors who marry or join the military before they turn 18. Georgia allows individuals as young as 14 to execute a will. In the vast majority of states, however, minors are unable to devise their assets simply because they are minors. When a minor dies, the minor's heirs (typically, the parents) inherit any of the decedent's assets.

Digital assets add another layer of complexity to the capacity issue because minors contract with digital asset providers when they enter into a terms of service agreement and begin to use the online platform. Under the common law, minors generally have a right to enter into contracts but may later disaffirm a contract using the infancy doctrine. The infancy doctrine aims to protect minors from their own foolishness in entering into an exploitative contract by allowing a minor to void or disaffirm the contract, but it requires a minor to return the benefit of a contract in order to disaffirm it. Few cases exist where minors have tried to disaffirm a contract with an online service provider, but in those we have seen, courts are hesitant to allow minors to disaffirm a contract because the minors have retained the benefits of using the program. Natalie

\section{Minors do not have the legal capacity to devise digital assets, but they do have the ability to contract with online vendors.}

\section{Banta, Minors and Digital Asset Succession,} 104 Iowa L. Rev. _ (2019).

Thus, minors do not have the legal capacity to devise digital assets, but they do have the ability to contract with online vendors and can decide what should happen to their digital assets if the company allows that as part of its contract with the minor. It is unlikely that a court would disaffirm the contract under the infancy doctrine at the death of a minor because a deceased minor could not return the benefit of the bargain of using digital assets; thus, the minor's accounts would continue to be controlled by the terms of service agreement.

A few states have enacted digital asset laws that apply specifically to minors. As noted in the introduction, in 2013, Virginia became one of the first-and only-states to do so. Virginia passed legislation to accommodate parents seeking access to their child's accounts. The law singled out the personal representatives of deceased minors, giving them access to the minor's electronic communications. Since then, Virginia has adopted RUFADAA, which applies to everyone's digital assets, not just minors. By enacting RUFADAA and repealing the previous legislation, it is again unclear in Virginia whether parents may insist on obtaining access to their deceased child's digital assets if the terms of service agreement forbids access. A few other states have addressed minors and digital assets in the context of guardianships. For example, Michigan explicitly includes minors as those to whom RUFADAA might apply in its definition of a "protected person." Mich. Comp. Laws Ann. § 700.1002(ee)(iii) (2018). Similarly, Tennessee's version of RUFADAA includes a section: "Disclosure of digital assets to guardian or conservator of a minor or person with a disability." Tenn. Code Ann. § 35-8-114 (2018). In discussing a guardian's power, North Carolina recognizes that it includes the ability to access the ward's digital assets. N.C. Gen. Stat. Ann. § 35A-1252.

\section{Minors Under Age 13}

It is important to note that internet law does not treat all minors under the age of 18 the same. For minors under the age of 13 , federal law imposes another limitation on their use of digital assets. In 1998, Congress enacted COPPA, the Children's Online Privacy Protection Act. 15 U.S.C. §§ 6501-6506 (1998). COPPA was designed to foster parental supervision of the information that online businesses collect from children. Under COPPA, online businesses that are directed to children under 13 or website services that know they are serving children that age are required to obtain parental consent before they can collect personal information from children and to develop procedures to protect the privacy of the information they collect. The FTC has regulatory authority to enforce COPPA. To prevent any difficulties with COPPA regulations, many online service providers block anyone under age 13 from signing up and by asking users to provide their birth dates when they sign up. Nonetheless, notwithstanding a website's prohibition, children under 13 do sign up for some of these websites, so fiduciaries cannot assume that children under 13 do not have such accounts. For example, Facebook and Instagram require anyone who creates an account to be at least 13 , but the authors know of many sixth graders who have their own Facebook pages and Instagram accounts.

\section{Estate Planning for Minors and Digital Assets}

So how should estate planners approach these issues? When estate planners meet with clients who have minor children, the 
discussion should include not just issues surrounding the financial and physical care of the children if the parents are no longer able to do so, but also matters concerning the minors' digital assets. That, in turn, means that parents may want to set out their wishes for controls on their children's digital accounts based on the parent's own incapacity or death and need to establish the means for management of their children's digital accounts if their children are incapacitated or die. (If it's difficult to discuss a client's death, it is even more emotionally fraught to discuss their children's incapacity or death.) Parents may want access to the minor's digital assets for the sentimental reasons discussed earlier, but also to prevent identity theft and, potentially, collect the minor's financial records. Consequently, there are certain steps that clients should take to protect their children's-and their own-interests.

The first, and most critical, step is to encourage parents to talk about these issues with their children, to know what their children are doing online, and to respect their children's intent. Regardless of the legal protections or restrictions, parents should discuss issues of online privacy with their children. They can commit to fulfilling their children's wishes in the event of their deaths, but only if they know what their children would have wanted. One of the authors began these discussions with her children when they were in high school; her daughters told her they preferred that she never have access to their digital assets, but each wanted her sibling to have access. They also did not want to share what kinds of digital accounts they had opened, although they were willing to provide the passwords to their computers. It was hard to hear as a parent, but it was a useful, clarifying conversation.

Second, once the conversation has started, parents can encourage their children to take advantage of the few online tools that exist. Facebook offers the Legacy Contact option, and Google offers an Inactive Account Manager.

Third, to ensure that there is a written record, estate planners can counsel clients to encourage their children to execute statements of intent. These statements may name the parent (or a sibling) as digital asset fiduciary, or the statement may indicate the minors want their digital assets destroyed. The language of any such statement should be tailored to the child's age. Example statements follow:

1. Digital Assets to be preserved. My parent/sibling/best friend has my permission to take control of, and have access to: (1) my computer, phone, or similar electronic devices, and anything that I have stored on them; and (2) my digital assets and accounts, including email, social media, music, photographs, and videos. My parent/sibling/best friend can do whatever they think is best with all of this. OR

2. Digital Assets to be deleted (check all that apply):

- I would like all of my digital assets to die with me.

- I would like all of my digital devices to be returned to their factory condition, with any of my personal data deleted.

- I would like any access to my digital assets, such as any email, social media, or gaming accounts, to be blocked, with no one, including my personal representative, able to access such accounts.

- I would like all my digital accounts deleted.

Additional suggestions, focused on adults, are available in Sasha A. Klein and Mark R. Parthemer's article, Who Will Delete the Digital You? Understanding Fiduciary Access to Digital Assets, Prob. \& Prop., Vol. 30, No. 4 (July/Aug. 2016); and in Naomi Cahn, Matt Savarare, and John Wintermute's forthcoming "Management of a Minor's Digital Assets in the Event of Incapacity or Death," in Tax, Estate, and Lifetime Planning for Minors, 2nd ed. (ed. Carmina D'Aversa forthcoming 2019).

If minors don't want a parent to have access, but a parent is appointed as fiduciary, then there is a conflict between respecting the minor's stated intent and effectuating the fiduciary role. Even in this situation, a parent has only limited access to the contents of stored communications under RUFADAA. It is unclear whether RUFADAA applies to minors as "users" or account holders in a way that would allow a minor to state a binding testamentary intent, especially because RUFADAA expressly states that it does not change any other law. If RUFADAA applies to minors as users of an account, it has strengthened their privacy rights after death. Parents, acting as fiduciaries, would not be able to override the stated and binding testamentary intent expressed by the minor. If RUFADAA does not apply, parents would make the same arguments for access as in the Germany and Virginia cases discussed above, advocating for access as an inheritance right under the common law and arguing that their children lacked legal capacity to execute a testamentary instrument regarding their digital assets.

\section{The Future of Minors and Digital Asset Planning}

Minors' use, creation, and accumulation of digital assets could prompt a reevaluation of our laws preventing minors from devising these assets, potentially carving out an explicit exception to other laws concerning capacity to execute testamentary instruments. As estate planners, we must consider how best to address our clients' and their children's desires concerning these issues. Granting minors legal capacity to devise digital assets will not necessarily change the outcome in a significant number of cases. If we can use adults as a comparison, only 50 percent of adults exercise their right to devise property. Even if we grant minors the right to devise their digital assets, they may not exercise the right. For the minors who do exercise their right to devise, it is unlikely that they will die before they reach the age of majority.

As estate planners, however, we plan for the likely and unlikely events in our clients' lives. We have the power to encourage minors to express their desires regarding their digital assets and honor their intent. In doing so, we promote freedom of succession, property rights, and privacy interests-and better parent-child communication. 